\title{
The Effect of Lined Circular Planting Methods of Sweet Corn (Zea mays Saccharata) on Diversity and Density of Weed Species
}

\author{
Lutfy Ditya Cahyanti* dan Use Etica \\ Universitas Darussalam Gontor, Ponorogo, Jawa Timur, Indonesia. 63471 \\ Corresponding author: lutfyditya@unida.gontor.ac.id
}

Received December 01, 2019; revised December 23, 2019; accepted June 30, 2020

\begin{abstract}
The objective of the research to determine the effect of row circle method on population and diversity of weed in sweet corn. This research was conducted in the Sub District of Siman, District of Siman, Ponorogo The research used a randomized block design (CBD) with 4 kinds of planting spaces included $\mathrm{J} 1=8$ plant/(60x80) $\mathrm{cm} 2, \mathrm{~J} 2=16 \mathrm{plant} /(60 \mathrm{x} 80) \mathrm{cm} 2, \mathrm{~J} 3=12$ plant $/(60 x 80) \mathrm{cm} 2, \mathrm{~J} 4=1 \mathrm{plant} /(60 \mathrm{x} 80) \mathrm{cm} 2, \mathrm{~J} 5=1 \mathrm{plant} /(60 \mathrm{x} 80) \mathrm{cm} 2$ with mowing. Each experimental unit was repeated 5 times so that there were 25 units. The observation was done on the Summed Dominance Ratio (SDR) of weeds on 21,28, 35 and 42 DAP (day after planting). Largest SDR was found in Cynodon dactylon (54,23\%) followed by broadleaf grass group (Phyllanthus nirurii, 40,5\%), and Sphenoclea zeylanica $(34,2 \%)$. Various planting system influenced weed species diversity. The number of weed species in 1 plant/(60x80) $\mathrm{cm} 2$ treatment was six species and higher than 8 plant/(60x80) $\mathrm{cm} 2,16$ plant/(60x80) cm2, 12 plant/(60x80) $\mathrm{cm} 2$ and 1 plant/(60x80) $\mathrm{cm} 2$ with mowing treatment which has three species.
\end{abstract}

Keywords: Sweet corn, Weed, Crop, Species, Density

ABSTRAK

Pengaruh Metode Tanam Lingkar Berjajar pada Jagung Manis (Zea mays Saccharata) terhadap Keanekaragaman dan Kepadatan Species Gulma

Penelitian ini bertujuan untuk mengetahui pengaruh metode tanam lingkar berjajar tanaman jagung manis terhadap populasi dan keragaman gulma. Penelitian ini dilakukan di Desa Siman, Kecamatan Siman, Kabupaten Ponorogo. Penelitian ini dilakukan dengan menggunakan Rancangan Acak Kelompok (RAK) dengan 4 jenis metode tanam lingkar berjajar, yaitu J1 $=8 \operatorname{tanaman} /(60 \times 80) \mathrm{cm} 2, \mathrm{~J} 2=16 \operatorname{tanaman} /(60 \times 80) \mathrm{cm} 2, \mathrm{~J} 3=12 \operatorname{tanaman} /(60 \times 80) \mathrm{cm} 2, \mathrm{~J} 4=1 \operatorname{tanaman} /(60 \times 80) \mathrm{cm} 2, \mathrm{~J} 5=$ 1 tanaman/(60x80) $\mathrm{cm} 2$ dengan penyiangan. Setiap unit perlakuan diulang 5 kali sehingga dihasilkan 25 petak penelitian. Pengamatan dilakukan pada Summed Dominance Ratio (SDR) masing-masing gulma pada 21,28, 35 dan 42 HST (hari setelah tanam). Gulma dengan SDR terbesar pada pengamatan 42 HST adalah Cynodon dactylon (54,23 \%) diikuti oleh kelompok gulma berdaun lebar (Phyllanthus nirurii, 40,5\%), dan Sphenoclea zeylanica (34,2\%). Metode tanam lingkar berjajar mempengaruhi keanekaragaman spesies gulma tanaman jagung. Jumlah spesies gulma dalam perlakuan 1 tanaman/(60x80) $\mathrm{cm} 2$ ada enam jenis species gulma, yaitu lebih tinggi dari 8 tanaman/(60x80) $\mathrm{cm} 2,16 \operatorname{tanaman} /(60 \times 80)$ $\mathrm{cm} 2,12$ tanaman/(60x80) $\mathrm{cm} 2$ dan 1 tanaman/ $(60 \times 80) \mathrm{cm} 2$ dengan penyiangan dimana terdapat tiga jenis species gulma.

Kata Kunci: Jagung manis, gulma, tanaman, species, kepadatan

\section{PENDAHULUAN}

Jagung manis saat ini semakin populer dan banyak dikonsumsi oleh masyarakat karena memiliki rasa yang lebih manis dibandingkan jagung biasa. Jagung manis juga bisa diolah menjadi berbagai alternatif makanan olahan. Kadar gula pada endosperm jagung manis sebesar 5-6\% dan kadar pati $10-11 \%$, sedangkan kadar gula pada jagung biasa hanya $2-3 \%$ atau setengah dari kadar gula jagung manis (Sirajuddin, 2010). Jagung manis memberikan keuntungan relatif tinggi bila dibudidayakan dengan baik karena harga jualnya yang lebih tinggi (Sudarsana, 2000). Muhsanati et al. (2006) menyatakan bahwa potensi hasil jagung manis yang seharusnya dapat mencapai 14-18 ton/ha, sedangkan produktifitas jagung manis di Indonesia rata-rata adalah 6-8 ton ha ${ }^{-1}$.

Salah satu penyebab rendahnya produktifitas tanaman jagung manis adalah akibat dari persaingan dengan gulma. Kehilangan hasil pada saat panen tanaman jagung berbeda mulai dari 28-93\% bergantung pada tipe gulma serta jumlah gulma yang ada dipertanaman serta durasi keberadaan gulma untuk berkompetisi dengan tanaman budidaya (Kandasamy, 2017). Beberapa jenis gulma yang berada di pertanaman jagung manis diantaranya Digitaria sanguinalis (1.) Scop., Setaria faberi Herrm., Amaranthus hybridus L. Panicum miliaceum, Ambrosia trifida and Sinapis arvensis (Silvernail, 2005).

Tanaman jagung manis secara umum dibudidayakan dengan sistem monokultur dengan jarak tanam yang cukup lebar (Asih et al., 2018). Gulma dan tanaman mempunyai kebutuhan dasar yang sama untuk pertumbuhan dan perkembangannya, yaitu: air, unsur hara, cahaya, ruang tumbuh dan $\mathrm{CO}_{2}$ (Sukman \& Yakup, 1991). Keberadaan gulma pada pertanaman akan menyebabkan kehilangan panen 
(Dalley et al., 2006) hal ini karena kompetisi dalam penggunaan cahaya matahari, unsur hara, karbon dioksida, dan meningkatkan biaya dalam pemeliharaan tanaman. (Khatam et al., 2013).

Menurut Tjitrosoedirdjo et al. (1984) untuk pertumbuhan satu ton gulma lebih banyak dibutuhkan air dan hara daripada untuk satu ton bagi kebanyakan tanaman lainnya. Air diserap tanaman dari dalam tanah kemudian sebagian besar diuapkan dan hanya sekitar $1 \%$ yang dipergunakan dalam proses fotosintesis. Untuk setiap 1 kilogram bahan organik, gulma membutuhkan 330-1900 liter air. Kebutuhan ini hampir 2 kali kebutuhan air tanaman (Sukman \& Yakup, 1991). Hendrival et al. (2014) menyatakan bahwa persaingan gulma pada awal pertumbuhan akan menurunkan kuantitas hasil tanaman budidaya dan persaingan pada saat akan mendekati panen akan menurunkan kualitas dari tanaman yang dibudidayakan.

Salah satu teknik budidaya yang bisa dilakukan untuk mengendalikan gulma adalah dengan pengaturan jarak tanam yang pada akhirnya akan menentukan kerapatan dan jumlah populasi tanaman di lahan pertanian (Froud-Williams, 2002). Salah satu metode untuk mengatur jarak tanam pada tanaman adalah dengan metode tanam lingkar berjajar yaitu sistem tanam melingkar yang akan mengatur populasi tanaman sebagai upaya untuk mengoptimalkan lahan untuk tanaman budidaya. Kerapatan jarak tanam berhubungan dengan populasi tanaman per satuan luas, dan persaingan antar tanaman dalam penggunaan cahaya matahari, air, unsur hara, dan ruang tumbuh, sehingga dapat berpengaruh terhadap pertumbuhan dan hasil tanaman. Jarak tanam yang rapat dengan populasi tanaman yang banyak akan menghambat pancaran cahaya ke permukaan lahan sehingga akan menghambat pertumbuhan gulma. Namun pada jarak tanam yang terlalu rapat mungkin tanaman budidaya akan memberikan hasil yang relatif kurang karena adanya kompetisi antar tanaman itu sendiri sehingga diperlukan penelitian yang tepat untuk mengetahui berapakah jarak tanam optimum yang dapat menurukan kepadatan gulma pada pertanaman sekaligus menghasilkan hasil panen yang optimal. Penurunan hasil tanaman jagung manis akibat persaingan dengan gulma sangat tergantung pada jenis gulma, tingkat kepadatan, waktu kompetisi sehingga perlu dilakukan analisis vegetasi untuk mengetahui gulma yang mendominasi pada suatu lahan budidaya. Oleh karena itu, penelitian ini bertujuan untuk mengetahui pengaruh metode tanam lingkar berjajar terhadap populasi dan keragaman gulma pada tanaman jagung manis.

\section{METODE PENELITIAN}

\section{Rancangan Penelitian.}

Penelitian ini dilakukan di Kecamatan Siman, Kabupaten Siman, Ponorogo. Penelitian ini dilakukan dengan menggunakan Rancangan Acak Kelompok (RAK) dengan 4 jenis pola tanam yaitu $\mathrm{J} 1=8$ tanaman $/(60 \times 80) \mathrm{cm}^{2}, \mathrm{~J} 2=16$ tanaman / (60x80) $\mathrm{cm}^{2}, \mathrm{~J} 3=12$ tanaman $/(60 \times 80) \mathrm{cm}^{2}, \mathrm{~J} 4=1$ tanaman $/(60 x 80) \mathrm{cm}^{2}, \mathrm{~J} 5=1$ tanaman $/(60 \times 80) \mathrm{cm}^{2}$ dengan penyiangan. Perlakuan penyiangan hanya dilakukan pada perlakuan J5. Setiap unit perlakuan diulang 5 kali sehingga dihasilkan 25 petak penelitian. Pengamatan jenis dan populasi gulma dilakukan pada pada 21,28, 35 dan 42 HST (hari setelah tanam).

\section{Identifikasi Gulma}

Identifikasi gulma yang ditemukan dari pengamatan petak perlakuan kemudian dilakukan dengan cara melihat secara visual bentuk morfologi gulma tersebut, kemudian dicocokkan dengan pustaka (Caton et.al., 2011) Langkah selanjutnya adalah mengelompokkan gulma berdasarkan spesies dan dihitung jumlahnya apabila sudah diketahui spesies gulma tersebut. Identifikasi dilakukan untuk memperoleh data keragaman dan dominasi jenis gulma pada lahan petak perlakuan.

Metode perhitungan yang digunakan untuk menganalisis vegetasi gulma yang tumbuh dominan adalah dengan metode summed dominance ratio (SDR) (Moenandir, 1993). Nilai SDR menunjukkan dominansi suatu gulma yang tumbuh disuatu pertanaman. Jika nilai SDR suatu gulma tinggi, maka dominansi gulma tersebut tinggi.

\section{HASIL DAN PEMBAHASAN}

Hasil analisa Summed Dominance Ratio (SDR) (Tabel 1.) menunjukkan bahwa spesies gulma yang ditemukan pada pengamatan sebelum tanam ada 7 species, yaitu Cynodon dactilon (42,2\%) disusul Cleome rutidosperma (25\%), Ageratum Conyzoides dengan 18,5\%, Digitaria sanguinalis (5,4\%), Amaranthus spinosus dengan 3,8\%, kemudian yang paling sedikit adalah Mimosa pudica dengan 2,2\% dan Portulaca oleeracea (2,4\%). Dari 7 species tersebut dapat dikelompokkan menjadi gulma berdaun sempit 2 species (Cynodon dactylon dan Digitaria sanguinalis) kemudian 5 species lainnya adalah gulma berdaun lebar sedangkan gulma rumput (grasses) tidak diketemukan.

Dari Tabel 1 juga dapat dilihat bahwa ada 4 jenis gulma yang ada dilahan pertanaman, dengan SDR terbesar atau gulma yang mendominasi yaitu Cynodon dactylon dengan rata-rata SDR 53,62\% (gulma berdaun sempit) dan tiga lainnya adalah gulma berdaun lebar yaitu Sphenoclea zeylanica (30,82\%), Portulaca oleracea $(27,8 \%)$ dan dengan SDR yang palong kecil adalah Phylanthus nirurii dengan 5,8\%. Sedangkan gulma Digitaria sanguinalis, Cleome rutidosperma, Mimosa pudica, Ageratum conyzoides dan Amaranthus spinosus tidak lagi ada di lahan pertanaman. 
Tabel 1. Nilai Summed Dominance Ratio (SDR) (\%) Gulma pada 21 hari setelah tanam (HST)

\begin{tabular}{|c|c|c|c|c|c|c|c|c|}
\hline No & Spesies & $\begin{array}{l}\text { SDR (\%) sebelum } \\
\text { olah tanah }\end{array}$ & $\begin{array}{c}\mathrm{SDR} \\
\mathrm{J}_{1}\end{array}$ & $\begin{array}{c}\text { SDR } \\
\mathrm{J}_{2}\end{array}$ & $\begin{array}{c}\text { SDR } \\
\mathrm{J}_{3}\end{array}$ & $\begin{array}{c}\text { SDR } \\
\mathrm{J}_{4}\end{array}$ & $\begin{array}{l}\mathrm{SDR} \\
\mathrm{J}_{5}\end{array}$ & $\begin{array}{l}\text { Rata-Rata } \\
{\text { SDR } \mathrm{J}_{1}-\mathrm{J}_{5}}\end{array}$ \\
\hline 1 & Cynodon dactylon & 42,2 & 89 & 28 & 60 & 16,8 & 74,3 & 53,62 \\
\hline \multirow[t]{2}{*}{2} & Digitaria & & & & & & & \\
\hline & sanguinalis & 5,4 & & & & & & \\
\hline \multirow[t]{2}{*}{3} & Cleome & & & & & & & \\
\hline & rutidosperma & 25 & & & & & & \\
\hline 4 & Mimosa pudica & 2,7 & & & & & & \\
\hline \multirow[t]{2}{*}{5} & Ageratum & & & & & & & \\
\hline & $\begin{array}{l}\text { conyzoides } \\
\text { Amaranthus }\end{array}$ & 18,5 & & & & & & \\
\hline 6 & spinosus & 3,8 & & & & & & \\
\hline \multirow[t]{2}{*}{7} & Portulaca & & & & & & & \\
\hline & oleracea & 2,4 & & 16 & & 39,6 & & 27,8 \\
\hline \multirow{3}{*}{$\begin{array}{l}8 \\
9\end{array}$} & Phylanthus nirurii & & & & & 5,8 & & 5,8 \\
\hline & Sphenoclea & & & & & & & \\
\hline & zeylanica & & 11 & 56 & 40 & 37,8 & 9,3 & 30,82 \\
\hline & Total & 100 & 100 & 100 & 100 & 100 & 100 & \\
\hline
\end{tabular}

Dari data Tabel 1 juga dapat dilihat bahwa pada umur $21 \mathrm{HST}$, lahan pertanaman jagung manis dengan kepadatan populasi paling sedikit yaitu perlakuan 1 tanaman / (60x80) $\mathrm{cm}^{2}$ ditemukan paling banyak species gulma yaitu 4 species. Sedangkan pada perlakuan 8 tanaman / $(60 x 80) \mathrm{cm}^{2}, 12$ tanaman / $(60 \times 80) \mathrm{cm}^{2}$ dan 1 tanaman / $(60 \times 80) \mathrm{cm}^{2}$ dengan penyiangan hanya ditemukan 2 species gulma. Hal ini membuktikan bahwa kerapatan populasi tanaman jagung manis berpengaruh pada populasi dan keragaman gulma yang ada, sesuai dengan literatur yang menyebutkan bahwa jarak tanam yang rapat akan meningkatkan daya saing tanaman budidaya terhadap gulma karena tajuk tanaman budidaya akan menghambat pancaran cahaya ke permukaan lahan sehingga akan menghambat pertumbuhan gulma sekaligus laju evaporasi pada lahan pertanaman dapat ditekan (Resiworo, 1992).

Data pengamatan SDR pada umur 28 hst (Tabel 2) menunjukkan bahwa pada perlakuan 1 tanaman/(60x80) $\mathrm{cm}^{2}$ diketemukan paling banyak species gulma yaitu species sedangkan pada perlakuan 8 tanaman / $(60 \times 80) \mathrm{cm}^{2}, 16$ tanaman / $(60 \times 80) \mathrm{cm}^{2}$, 12 tanaman / $(60 \times 80) \mathrm{cm}^{2}$, dan 1 tanaman / (60x80) $\mathrm{cm}^{2}$ dengan penyiangan ditemukan 2 species. Munculnya jenis spesies gulma yang tumbuh pada lokasi penelitian semakin memberi tekanan pada pertumbuhan tanaman jagung, di mana kompetisi untuk mendapatkan cahaya, suhu, unsur hara, air dan ruang tumbuh semakin kuat (Nurlaili, 2010).

Dari data pengamatan 28 hst juga diketahui bahwa gulma yang mendominasi pada lahan pertanaman jagung manis adalah Cynodon Dactylon dengan SDR rata-rata 50,1\%. Sedangkan gulma lain yang ditemukan pada petak percobaan adalah Sphenoclea zeylanica (41,3\%), Ageratum conyzoides
(20\%), Cleome rutidosperma (7,9\%) Amaranthus spinosus dengan SDR 7,5\%. Sedangkan gulma lain dengan SDR rendah adalah Digitaria sanguinalis (4\%) dan Portulaca oleracea 3,6\%.

Dari data tersebut dapat diketahui bahwa gulma yang banyak ditemukan pada lahan tanaman jagung manis adalah gulma berdaun lebar. Hal ini sesuai dengan penelitian Irfam (1999) yang menjelaskan bahwa gulma yang ada dipertanaman jagung diantaranya Ageratum conyzoides, Digitaria sanguinalis, Phylanthus niruii dan Cyperus rotundus. Lahan tanaman jagung yang belum berumur 3 bulan biasanya banyak ditumbuhi oleh berbagai jenis gulma, karena pada lahan tersebut masih banyak terdapat ruang tumbuh yang masih kosong dimana gulma dengan mudah dapat tumbuh pada lahan tersebut. Hal ini karena sifat dari gulma itu sendiri dimana dapat tumbuh dan berkembang pada berbagai kondisi lingkungan (Kastanja, 2015).

Data pengamatan pada 35 HST yang disajikan pada Tabel 3 menunjukkan bahwa jumlah species gulma paling banyak diketemukan pada petak perlakuan 1 tanaman / $(60 \times 80) \mathrm{cm}^{2}$ yaitu 4 species gulma, yang terdiri dari Cynodon dactylon, Digitaria sanguinalis, Phylanthus nirurii dan Sphenoclea zeylanica. Sedangkan perlakuan lainnya $\mathrm{J} 1=8$ tanaman $/(60 \times 80) \mathrm{cm}^{2}, \mathrm{~J} 2=16$ tanaman $/(60 \times 80)$ $\mathrm{cm}^{2}, \mathrm{~J} 3=12$ tanaman $/(60 \times 80) \mathrm{cm}^{2}$ dan $\mathrm{J} 5=1$ tanaman / $(60 \times 80) \mathrm{cm}^{2}$ dengan penyiangan hanya diketemukan 2 species, yaitu Cynodon dactylon dan Sphenoclea zeylanica. Semakin banyak populasi tanaman budidaya, gulma akan yang kalah dalam kompetisi dengan tanaman budidaya semakin tertekan akibatnya gulma yang tumbuh semakin sedikit. 
Tabel 2. Nilai Summed Dominance Ratio (SDR) Gulma pada 28 hari setelah tanam (HST)

\begin{tabular}{|c|c|c|c|c|c|c|c|c|}
\hline & & SDR sebelum olah & & SDR & SDR & & & Rata-Rate \\
\hline No & Spesies & tanah & $\mathrm{SDR} \mathrm{J}_{1}$ & $\mathrm{~J}_{2}$ & $\mathrm{~J}_{3}$ & $\mathrm{SDR} \mathrm{J}_{4}$ & $\mathrm{SDR} \mathrm{J}_{5}$ & $\mathrm{~J}_{1}-\mathrm{J}_{5}$ \\
\hline 1 & $\begin{array}{l}\text { Cynodon dactylon } \\
\text { Digitaria }\end{array}$ & 42,2 & 44,4 & 59 & 59,3 & 26 & 61,8 & 50,1 \\
\hline 2 & $\begin{array}{l}\text { sanguinalis } \\
\text { Cleome }\end{array}$ & 5,4 & & & & 4 & & 4 \\
\hline 3 & rutidosperma & 25 & & & & 7,9 & & 7,9 \\
\hline 4 & $\begin{array}{l}\text { Mimosa pudica } \\
\text { Ageratum }\end{array}$ & 2,7 & & & & & & \\
\hline 5 & $\begin{array}{l}\text { conyzoides } \\
\text { Amaranthus }\end{array}$ & 18,5 & & & & 20 & & 20 \\
\hline 6 & $\begin{array}{l}\text { spinosus } \\
\text { Portulaca }\end{array}$ & 3,8 & & & & 7,5 & & 7,5 \\
\hline 7 & $\begin{array}{l}\text { oleracea } \\
\text { Sphenoclea }\end{array}$ & 2,4 & & & & 3,6 & & 3,6 \\
\hline \multirow[t]{2}{*}{8} & zeylanica & & 55,6 & 41 & 40,7 & 31 & 38,2 & 41,3 \\
\hline & Total & 100 & 100 & 100 & 100 & 100 & 100 & \\
\hline
\end{tabular}

Pertumbuhan tanaman budidaya dengan gulma yang saling berhimpitan, daun-daun yang mampu menaungi salah satu daripadanya akan berperan sebagai penghambat. Bila kanopi tanaman budidaya sudah bisa menaungi gulma, maka gulma akan tertekan hidupnya sebab laju pertumbuhan gulma tak dapat dikembangkan dan demikian sebaliknya (Moenandir, 1998). Sedangkan menurut Ilham (2014) Sinar matahari yang tak terhalang dangat mempengaruhi pertumbuhan gulma, cahaya matahari sumber energi utama untuk berlangsungnya proses fotosintesis.

Dari data Tabel 3 dapat diketahui bahwa gulma yang paling mendominasi adalah Cynodon dactylon dengan nilai SDR rata-rata semua perlakuan $45,2 \%$. Kemudian diikuti Sphenoclea zeylanica (44\%), Phylanthus nirurii $(33,4 \%)$ dan Digitaria sanguinalis (23\%). Banyak faktor dapat mempengaruhi jenis dan keragaman gulma pada suatu lahan, diantaranya jenis tanah, kultur teknis, dan ketinggian tempat. Sembodo (2010) menyatakan bahwa tindakan kultur teknis akan dapat mempengaruhi tinggi rendahnya tingkat persaingan gulma terhadap tanaman budidaya. Selain itu,kerapatan gulma yang tumbuh pada lahan pertanian bervariasi menurut musim.

Data pengamatan pada umur tanaman 42 hst yang tersaji pada tabel 4 menunjukkan bahwa pada species gulma paling banyak ditemukan pada perlakuan 1 tanaman / $(60 \times 80) \mathrm{cm}^{2}$ dengan 7 species gulma, yaitu Cynodon dactylon, Digitaria sanguinalis, Cleome rutidosperma, Ageratum conyzoides, Portulaca oleracea, Phylanthus nirurii dan Sphenoclea zeylanica, Jarak tanam yang terlalu lebar dapat memberikan keleluasaan bagi gulma untuk tumbuh dan berkembang pada barisan tanaman, sementara jarak tanam yang terlalu sempit dapat mengakibatkan terjadinya kompetisi intraspesifik. Hasil penelitian menunjukkan bahwa peningkatan kepadatan tanaman dengan mengurangi jarak tanam dapat menekan pertumbuhan gulma (Rao, 2000).

Adapun pada perlakuan 8 tanaman/(60x80) $\mathrm{cm}^{2}$ terdapat 3 species gulma, yaitu Digitaria sanguinalis, Cleome rutidosperma, dan Sphenoclea zeylanica. Dari hasil pengamatan juga dapat diketahui bahwa pada perlakuan 16 tanaman / $(60 \times 80) \mathrm{cm}^{2}$ diketemukan 3 species gulma yaitu Digitaria sanguinalis, Cleome rutidosperma dan Sphenoclea zeylanica, sedangkan pada perlakuan 16 tanaman / (60x80) $\mathrm{cm}^{2}$ diperoleh 3 species gulma, yaitu Ageratum conyzoides, Phylanthus nirurii dan Sphenoclea zeylanica.

Dari data juga dapat diketahui bahwa pada perlakuan 12 tanaman / $(60 \times 80) \mathrm{cm}^{2}$ terdapat 3 species gulma yang diketemukan di lahan percobaan, yaitu Cynodon dactylon, Phylanthus nirurii, dan Phylanthus nirurii. Pada perlakuan 1 tanaman / (60x80) $\mathrm{cm}^{2}$ dengan penyiangan hanya diketemukan satu jenis gulma yaitu Cynodon dactylon. Penyiangan gulma ialah kegiatan pengelolaan gulma yang digunakan untuk mengurangi adanya kompetisi antara gulma dengan tanaman budidaya.

Penyiangan gulma juga bisa disebut sebagai tindakan pencegahan maupun tindakan pengendalian gulma yang didasarkan pada fase pertumbuhan gulma. Penyiangan yang dilakukan secara berulang dapat menekan pertumbuhan gulma. Dari tabel 3 juga dapat diketahui bahwa rata-rata SDR gulma yang terbesar adalah Cynodon dactylon (54,23\%), kemudian diikuti Phylanthus nirurii (40,5\%), Sphenoclea zeylanica 
dengan nilai SDR 34,25\%. Berikutnya, nilai rata-rata SDR untuk gulma Digitaria sanguinalis $(22,4 \%)$, Cleome rutidosperma dengan nilai SDR 20,35\%.
Kemudian nilai rata-rata SDR gulma Ageratum conyzoides adalah $14,7 \%$ sedangkan Portulaca oleracea memiliki nilai SDR $4,4 \%$.

Tabel 3. Nilai Summed Dominance Ratio (SDR) Gulma pada 35 hari setelah tanam (HST).

\begin{tabular}{|c|c|c|c|c|c|c|c|c|}
\hline No & Spesies & $\begin{array}{l}\text { SDR sebelum olah } \\
\text { tanah }\end{array}$ & $\mathrm{SDR} \mathrm{J}_{1}$ & $\begin{array}{c}\text { SDR } \\
\mathrm{J}_{2}\end{array}$ & $\begin{array}{c}\mathrm{SDR} \\
\mathrm{J}_{3}\end{array}$ & $\mathrm{SDR} \mathrm{J}_{4}$ & $\mathrm{SDR} \mathrm{J}_{5}$ & $\begin{array}{c}\text { Rata-Rata } \\
\mathrm{J}_{1}-\mathrm{J}_{5}\end{array}$ \\
\hline 1 & Cynodon dactylon & 42,2 & 64 & 66 & 33,4 & 29,4 & 33,4 & 45,2 \\
\hline 2 & Digitaria & & & & & & & \\
\hline & sanguinalis & 5,4 & & & & 23 & & 23 \\
\hline 3 & Cleome & & & & & & & \\
\hline & rutidosperma & 25 & & & & & & \\
\hline 4 & Mimosa pudica & 2,7 & & & & & & \\
\hline 5 & Ageratum & & & & & & & \\
\hline & conyzoides & 18,5 & & & & & & \\
\hline 6 & Amaranthus & & & & & & & \\
\hline & spinosus & 3,8 & & & & & & \\
\hline 7 & Portulaca & & & & & & & \\
\hline & oleracea & 2,4 & & & & & & \\
\hline 8 & Phylanthus nirurii & & & & & 30,4 & & 30,4 \\
\hline 9 & Sphenoclea & & & & & & & \\
\hline & zeylanica & & 36 & 34 & 66,6 & 17,2 & 66,6 & 44 \\
\hline & Total & 100 & 100 & 100 & 100 & 100 & 100 & \\
\hline
\end{tabular}

Tabel 4. Nilai Summed Dominance Ratio (SDR) Gulma pada 42 hari setelah tanam (HST).

\begin{tabular}{|c|c|c|c|c|c|c|c|c|}
\hline No & Spesies & $\begin{array}{l}\text { SDR sebelum olah } \\
\text { tanah }\end{array}$ & $\mathrm{SDR} \mathrm{J}_{1}$ & $\begin{array}{c}\text { SDR } \\
\mathrm{J}_{2}\end{array}$ & $\mathrm{SDR} \mathrm{J}_{3}$ & $\mathrm{SDR} \mathrm{J}_{4}$ & $\mathrm{SDR}_{5}$ & $\begin{array}{c}\text { Rata-Rata } \\
\mathrm{J}_{1}-\mathrm{J}_{5} \\
\end{array}$ \\
\hline 1 & Cynodon dactylon & 42,2 & & & 29,7 & 33 & 100 & 54,23 \\
\hline 2 & $\begin{array}{l}\text { Digitaria } \\
\text { sanguinalis }\end{array}$ & 5,4 & 36,5 & & & 8,3 & & 22,4 \\
\hline 3 & $\begin{array}{l}\text { Cleome } \\
\text { rutidosperma }\end{array}$ & 25 & 11,2 & & & 29,5 & & 20,35 \\
\hline 4 & Mimosa pudica & 2,7 & & & & & & \\
\hline 5 & $\begin{array}{l}\text { Ageratum } \\
\text { conyzoides }\end{array}$ & 18,5 & & 25,4 & & 4 & & 14,7 \\
\hline 6 & $\begin{array}{l}\text { Amaranthus } \\
\text { spinosus }\end{array}$ & 3,8 & & & & & & \\
\hline 7 & $\begin{array}{l}\text { Portulaca } \\
\text { oleracea }\end{array}$ & 2,4 & & & & 4,4 & & 4,4 \\
\hline 8 & Phylanthus nirurii & & & 33,4 & 47,6 & & & 40,5 \\
\hline 9 & $\begin{array}{l}\text { Sphenoclea } \\
\text { zeylanica }\end{array}$ & & 52,3 & 41,2 & 22,7 & 20,8 & & 34,25 \\
\hline & Total & 100 & 100 & 100 & 100 & 100 & 100 & \\
\hline
\end{tabular}

Dari Tabel 4 diketahui bahwa gulma yang paling mendominasi pada semua perlakuan jagung manis pada umur 42 hst adalah Cynodon dactylon. Cynodon dactylon (rumput grinting) banyak ditemukan di daerah tropika (Jayadi, 1991). C. dactylon mampu bertahan dalam kondisi lingkungan ekstrim dibandingkan dengan gulma jenis lain karena memiliki biji yang kecil dan mudah berkembang biak dengan cepat (Gilliand et al., 1971) C.dactylon mampu bertahan hidup di lahan yang tandus dalam musim kemarau sehingga $C$. dactylon menjadi gulma yang sangat merugikan pada lahan pertanian maupun perkebunan. Rumput Grinting adalah jenis rumput yang nemiliki kemampuan tingi dalam hal bertahan hidup dibandingkan rumput jenis lain seperti teki, ataupun rumput gajah. Grinting mampu bertahan hidup di lahan yang tandus dalam musim kemarau meskipun pertumbuhannya tidak optimal. Rumput 
grinting akan tetap bertahan hidup setelah penyiangan atau pengolahan tanah selama akarnya masih bersinggungan dengan tanah (Huda, 2017). Pengendalian gulma harus ditujukan untuk menekan kerugian dan gangguan yang ditimbulkan oleh gulma agar pertumbuhan dan produksi tanaman tidak terganggu. Suatu gulma dikatakan merugikan karena dapat memberikan pengaruh negatif terhadap pertumbuhan tanaman budidaya disekitarnya. Jenis gulma ini sangat merugikan apabila tumbuh di pertanaman padi gogo, mampu melakukan persaingan, mengeluarkan efek alellopati, berkembang biak dengan cepat, dan sulit pengendaliannya.

\section{KESIMPULAN}

Gulma dengan Summed Dominance Ratio (SDR) terbesar pada pengamatan 42 hari setelah tanam (HST) adalah gulma berdaun sempit Cynodon dactylon $(54,23 \%)$ diikuti oleh kelompok gulma berdaun lebar (Phyllanthus nirurii, 40,5\%), dan Sphenoclea zeylanica $(34,2 \%)$.

Metode tanam lingkar berjajar mempengaruhi keanekaragaman spesies gulma tanaman jagung. Jumlah spesies gulma dalam perlakuan 1 tanaman/(60x80) $\mathrm{cm}^{2}$ ada enam jenis species gulma, yaitu lebih tinggi dari 8 tanaman/(60x80) $\mathrm{cm}^{2}, 16$ tanaman/(60x80) $\mathrm{cm}^{2}, 12$ tanaman/(60x80) $\mathrm{cm}^{2}$ dan 1 tanaman/(60 x 80) $\mathrm{cm}^{2}$ dengan penyiangan dimana terdapat tiga jenis species gulma

\section{UCAPAN TERIMA KASIH}

Ucapan terimakasih kami ucapkan kepada DRPM Kemenristekdikti yang telah membiayai penelitian ini melalui skema Penelitan Dosen Pemula dengan nomor kontrak 633/UNIDALPPM/SPK/IV/2019.

\section{DAFTAR PUSTAKA}

Asih SDN, Setiawan AN \& Sarjiyah. 2018. Weeds Growth in Various Population of CornPeanut Intercropping. Planta Tropika: Jurnal Agrosains. 6(1): 7-15.

Caton BP, Mortimer M, Hill JE, \& Johnson DE. 2011. Panduan Lapang Praktis Gulma Padi Asia. International Rice Research Institute. Makati City. pp. 129-132.

Dalley CD, Bernads ML, Kells JJ. 2006. Effect of weed removal timing and spacing on soil moisture in corn (Zea mays L.). Weed Technology. 20(2): 399-409.

Froud-Williams RJ. 2002. Weed Management Hand Book. Ninth Edition. Published for The British Crop Protection Council by Blackwell Science. pp. 180-198.

Gilliand HB, Holttum RE, \& Bor NL. 1971. A Revised Flora of Malaya vol. III, Grasses Malaya, HM, Burkill (ed), Auspies of The Botanic Garden.Singapore. pp. 116-125.
Hendrival, Zurrahmi, \& Abdul. 2014. Periode Kritis Tanaman Kedelai Terhadap Persaingan Gulma. Jurnal Floratek. 9: 6-13.

Huda S. 2017. Pengaruh Variasi Konesentrasi Ekstrak Daun Rumput Teki (Cyperus rotundus L.) Sebagai Bioherbisida Gulma Grinting. Skripsi. Fakultas Tarbiyah dan Keguruan UIN Mataram.

Ilham J. 2014. Identifikasi dan Distribusi Gulma di Lahan Pasir Pantai Samas, Kabupaten Bantul, Daerah Istimewa Yogyakarta. Planta Tropika:Jurnal Agrosains. 2(2): 90-98.

Irfam M. 1999. Respon Tanaman Jagung (Zea mays L) Terhadap Pengolahan Tanah dan Kerapatan Tanam pada Tanah Andisol dan Ultisol. Thesis. Pasca Sarjana Universitas Sumatra Utara, Medan. pp. 7-13.

Jayadi S. 1991. Tanaman makanan ternak tropika.Institut Pertanian Bogor, Bogor. pp. 8-20.

Kandasamy S. 2017. Effect of Weed Management Practices on Weed Control Index, Yield and Yield Components of Sweet Corn. J Agri Res. 2(4): 3-8.

Kastanja A. 2015. Jenis dan Dominansi Gulma Pada Lahan Jagung Manis (Studi Kasus di Kecamatan Tobelo). Jurnal Agroforestri. 10(1): 7-13.

Khatam A, Khan MZ, Nawab K, Mian IA \& Ahmad W. 2013. Effect of various herbicides and manual control yield, yield components and weeds of maize. Weed Sci Res. 19(2): 209216.

Moenandir J. 1993. Ilmu Gulma. Raja Grafindo Persada. Jakarta. pp. 2-9.

Moenandir J. 1998. Persaingan Tanaman Budidaya dengan Gulma (Ilmu Gulma - Buku III). Rajawali Pers. Jakarta. pp. 15-22.

Muhsanati, Syarif \& Rahayu. 2006. Pengaruh Beberapa Takaran Kompos Tithonia terhadap Pertumbuhan dan Hasil Tanaman Jagung Manis (Zea Mays Saccharata). Jurnal Jerami. 2: 87-91.

Nurlaili. 2010. Respon Pertumbuhan Tanaman Jagung (Zea mays L.) dan Gulma Terhadap Berbagai Jarak Tanam. Agronobis. 2(4): 11-16.

Purba E. 2009. Keanekaragaman herbisida dalam pengendalian gulma Mengatasi Populasi Gulma Resisten dan Toleran Herbisida. Pidato Pengukuhan Jabatan Guru Besar. Medan : Universitas Sumatera Utara.

Rao VS. 2000. Principles of Weed Science. Science Publishers, Inc. California, USA. pp. 124135.

Resiworo JSD. 1992. Pengendalian gulma dengan pengaturan jarak tanam dan cara penyiangan pada pertanaman kedelai. Prosiding Konferensi Himpunan Ilmu Gulma Indonesia. Ujung Pandang. pp. 131-136. 
Sembodo DRJ. 2010. Gulma dan Pengelolaannya. Graha Ilmu. Yogyakarta. pp. 120-124

Silvernail A. 2005. Weed Management in Organic Sweet Corn. Horticultura Sciences. 40: 1925.

Sirajuddin M. 2010. Komponen Hasil dan Kadar Gula Jagung Manis (Zea mays saccharata) Terhadap pemberian Nitrogen dan Zat Tumbuh Hidrasil. Laporan Penelitian Mandiri. Fakultas Pertanian. Universitas Tadulako. Palu.
Sudarsana K. 2000. Pengaruh effective microorganism-4 (EM-4) dn kompos terhadap produksi jagung manis pada tanah entisols. Frontir. 32: 1-8.

Sukman \& Yakup. 1991. Gulma dan Teknik Pengendaliannya. Rajawali Pers. Jakarta. pp. 16-28.

Tjitrosoedirdjo S, Utomo IH \& Wiroatmodjo J. 1984. Pengelolaan gulma di perkebunan. Gramedia. Jakarta. pp. 25-29. 